\title{
Turning Point: \\ Coordinated Criminal Justice Reform in the Show-Me State Jon Marc Taylor
}

Challenging the status quo and injustice takes not only courage and conviction, but also creativity.

- Lisa Yun Lee

\section{PREFACE}

Concerted efforts at criminal justice reform have been underway for over two decades. Organizations such as MO-CURE, K.C. Criminal Justice Task Force, Missouri Citizens for Reform, Mothers of Incarcerated Sons \& Daughters and the NAACP, among others, have made valiant efforts to contest the prison industrial complex that has arisen in the state. Despite these well intentioned and passionately supported exertions, Missouri incarcerates on a proportional basis 25 percent more prisoners than Illinois and 40 percent more than Kansas, all the while with the sister states sharing similar rates of reported crime. Thus, Missourians are no "safer" than Kansans or Illini, but publicly finance - at the expense of all other educational and social services - a penal system at the least a third larger than necessary.

Alas, to date, the best that can be discerned of the multitudinous of reform efforts is that they have restrained the prison-industrial complex from growing even larger than it already is. From the perspective of one from the inside looking out, what I have seen are well meaning efforts that lack coordination of limited resources and a coherent strategy that can produce a cohesive effort for systematic change. What this paper proposes is a means to develop that cohesive strategy that can affect positive systemic criminal justice reform in the Show-Me State.

By utilizing, as a "menu of successful options" from the Smart Reform is Possible: States Reducing Incarceration Rates and Costs While Protecting Communities report compiled by the ACLU (2011), a coalition of Missouricentered groups and organizations can develop a cohesive criminal justice reform agenda, collectively marshal and effectively focus their limited resources in a concerted lobbying campaign to effect systemic change, the end goal of which is to significantly reduce the onerous and ultimately socially-destructive prison-industrial complex. 


\section{INTRODUCTION}

In the past few years, the public and policymakers across the political spectrum have started to recognize that criminal justice reform is both necessary and politically viable. Lawmakers have steadily become interested in alternatives to incarceration that have proven to produce more effective public safety outcomes. "Get tough on crime" politicians are talking instead about being "smart on crime", and legislators are enacting bills supporting evidence-based programs.

Present reform efforts in several states have undermined the erroneous and misguided notion that mass incarceration is necessary to protect our public safety. Below is a selection of recommendations for legislative and administrative reforms that states should implement to reduce their incarcerated populations and corrections budgets, while keeping our communities safe. These recommendations cover: systemic reforms to the criminal justice apparatus as a whole; "front-end" reforms focusing on reducing the number of people entering jails and prisons; and "back-end" reforms that increase the number of people exiting and staying out of prison. These recommendations are by no means exhaustive, but aim to provide advocates and lawmakers with a few key evidence-based and politicallytested reforms from which to craft a state-specific legislative agenda for criminal justice reform.

As highlighted by the significant success of criminal justice reform discussed here, it is more than possible for a state to limit its reliance on prisons, reduce its incarceration budget, and promote public safety and fairness. As states across the country are realizing that reducing prison populations and corrections budgets is a necessity, they can look to the examples in this report as ways to reform their criminal justice systems with promising results. These reforms are "evidence-based" (i.e. backed up by social science and economic evidence proving their success) and show that mass incarceration is not necessary to protect public safety. It is possible to formulate criminal justice reforms that will garner bipartisan legislative and governmental support, as well as support within our communities, and achieve reductions in prison populations and budgets without compromising public safety. A state can select reforms from a broad menu of changes, but must first take the step to commit to reform. 


\section{PURPOSE}

The purpose of this exposition is to outline a strategy of how to develop a more effective criminal justice reform campaign that has been achieved to date. With two decades of disparate association/group establishment (e.g. MO-CURE) and organizational infrastructure development (e.g. membership growth), the largely uncoordinated movement lobbies have little synergy and at times works at cross-purposes. The multi-faceted benefits of developing a unified reform platform are:

- Unified, multi-level reform agenda;

- $\quad$ Simplified and more targeted messaging;

- More effective limited resource allocation;

- Special/single-issue organization goals integrated within the holistic strategy; and

- Potential for greater organizational investment by developing a clear message, defined strategy and accumulate successes.

\section{CONCEPT}

The Smart Reform Is Possible (SRIP) report needs to be utilized as a collative tool from which to educate the presently loosely confederated criminal justice reform movement in the state and from which to determine Missouri-applicable reform options. Deploying the SRIP report, applicable effective and proven systemic "front-end" and "back-end" reform positions can be determined as to those best suited for implementation, addressing the conformity of the Missouri penal code and practices. The use of the SRIP report provides many benefits:

- A national, multi-state analysis of what has been implemented elsewhere;

- Specific legislation, sponsors and party-affiliation, synopsis of lobbying history, and subsequent results;

- Costs, savings, and further projected reforms, exampling how to develop similar successful approach;

- An acceptable, nonpartisan vehicle for reform-based organizations to collectively form around in determination of proven best agenda 
items for the construction of a unified criminal justice reform platform; and

- Names of specific legislations' sponsoring legislators, facilitating the consultation - if not possible endorsement recruitment - of similar Missouri-focused legislation.

- Upon ratification of a unified reform agenda, a coalition reform movement can determine most efficient allocation of its limited resources.

- Regardless of outcome of action to develop a unified reform agenda, the effort nonetheless will serve to strengthen the formation of such a coalition in future endeavours.

Upon ratification of a unified reform agenda, a coalition reform movement can determine the most efficient way to allocate its limited resources. Regardless of the outcome, the effort would nonetheless serve to strengthen the formation of such a coalition in the future.

\section{GOAL AND OBJECTIVES}

The ultimate goal is criminal justice reform that results in substantial reduction (a third or better) in the size of the state's prison industrial complex. To realize this dream, with all its attending socio-economic benefits, multiple subordinated goals and their objectives need to be attained.

\section{Goal I: Formation of Missouri Coalition for Criminal Justice Reform} (MC4CJR)

Objective 1: Designate coordinating clearing house (e.g. MO-CURE committee/contact person) to initiate coordination of coalition recruitment.

Objective 2: Contact and lobby every criminal justice reform organization and committee (e.g. faith-based committees/ ministries) to participate in MC4CJR.

\section{Goal II: Develop holistic criminal justice reform platform}

Objective 1: Disseminate/direct to SRIP report to every potential committee/group/organization coalition member for their consideration. 
Objective 2: Encourage submission of and collate agenda items from MC4CJR members to draft an initial collective platform.

Objective 3: Coordinate state-wide convention with delegates from all MC4CJR to refine the coalition's platform.

Objective 4: Conduct state-wide convention to: a) ratify the holistic reform platform; b) determine annual and 3-year timeline; and c) align MC4CJR members' resources for optimum synergistic results.

\section{Goal III: Initiate MC4CJR platform agenda}

Objective 1: Submit/support bills and/or policy amendments in furtherance of platform's agenda.

Objective 2: Have MC4CJR members participate in legislative "lobbying days".

Objective 3: Realize MC4CJR platform public informational communications (e.g. articles, op-eds, posters, sermons, speeches, event information booths, etc.).

\section{PROCEDURES}

Having MO-CURE as the state-wide membership encompassing organization and holistically-themed criminal justice reform organization in Missouri, it can utilize its network of contacts and vehicles to initiate recruitment of similar reform associations (e.g. NAACP prison branches), groups (e.g. K.C. Criminal Justice Task Force) and organizations (e.g. Mothers of Incarcerated Sons and Daughters), among others, to commence the development of a unified criminal justice reform platform. The process of reform implementation will entail three phases.

In the first phase, individual reform groups would obtain and disseminate copies of the SRIP report at www.aclu.org among its memberships. Utilizing members' particular expertise and networking contacts (e.g. elected officials, system professionals, etc.) they could select/develop systemic, front-end and back-end actions that best meet their goals. Next, each group could move to ratify their organization's agenda. Finally, they could participate in the proposed coalition convention with the objective of ratifying a holistic criminal justice reform platform. 
In the second phase, representatives from the various reform groups could initiate conference/video calls to share their platforms and to coordinate a convention. Each group could send delegates to the convention to adopt a focused criminal justice reform platform, addressing specific systemic, front-end and back-end reforms. Additionally, a three-year strategic plan for implementation of the reform agenda should be outlined, with resource coordination and each group's action contributions noted. Finally, an annual timeline for action step accomplishments (e.g. drafting of model legislation, coordinating membership' capitol lobbying tour, etc.) should be established, with all groups coordinating efforts to achieve greatest synergy of resource investment.

In the final phase, the participants could coordinate activities towards achieving their collective reform agenda. Organizations could continue to educate their memberships as to the issues, the reform platforms, and actions to be taken. Media messaging could be coordinated and organizations could utilize their resources to this end. All groups should coordinate their representation (the more members the better) during legislature lobbying days. Ongoing engagement with representative/senatorial contacts should be reported within the coalition for the opportunity for refined coordination. Finally, an annual conference call and/or convention should be held to analyze accomplishments, determine failures and amend approaches for greater success, and to better coordinate the forthcoming year, modifying goals and objectives as circumstances dictate.

\section{Mix-Stir-REPEAT.}

\section{CONCLUSION}

Admittedly, as drafted from this incarcerated and thus isolated venue, this proposal is the broadest sketching of what may be possible to achieve. On the other hand, all the pieces ranging from associations/committees/ ministries/organizations to cumulative membership in the thousands who have the most fervent interest and passion to change the ship of state that has created the behemoth of the prison industrial complex already exists.

What has been missing from the game has been a cohesive collaborative effort all striving in the same direction, sharing the same defined and enumerated objectives. The next evolution in criminal justice reform in the Show-Me State must involve such a broad-based coalition collectively 
moving the political pendulum to a more balanced, just and restorative criminal justice system. This outline can be a beginning to that day, if adopted and adapted by all those many other good people who can make the difference, changing the small part of the world in which we live.

\section{REFERENCE}

American Civil Liberties Association [ACLU] (2011) Smart Reform Is Possible: States Reducing Incarceration Rates and Costs While Protecting Communities, New York. Retrieved from $<$ https://www.aclu.org/criminal-law-reform/smart-reform-possiblestates-reducing-incarceration-rates-and-costs-while>.

\section{ABOUT THE AUTHOR}

Jon Marc Taylor, $\mathrm{PhD}$, has been a prisoner for over 30 years and has received The Nation / I.F. Stone and Robert F. Kennedy Journalism awards for his reporting on correctional issues. In 1989, Taylor's first piece in the Journal of Prisoners on Prisons appeared in Volume 2(1) and he has since remained a regular contributor to the journal. 